\title{
Upaya Meningkatkan Keterampilan Pukulan Forehand Smash Bulutangkis Menggunakan Metode Drill Variasi Bagi Atlet PB. Malang Badminton Club Kota Malang
}

\author{
Adinda Lutfi Setyawati, Oni Bagus Januarto*, Rama Kurniawan \\ Universitas Negeri Malang, Jl. Semarang No. 5 Malang, Jawa Timur, Indonesia \\ *Penulis korespondens, Surel: oni.bagus.fik@um.ac.id
}

Paper received: 3-2-2022; revised: 22-2-2022; accepted: 27-2-2022

\begin{abstract}
The purpose of this study was to improve the badminton forehand smash skills of athletes at PB. Malang Badminton Club Malang City. This research is a Sports Action Research (PTO). Data collection techniques used were interviews, questionnaires, observation, and tests. The analysis used is qualitative and quantitative data analysis. This research was conducted for 2 cycles, each cycle consisting of 5 meetings. The subjects used were 13 athletes. The results of this study indicate that in cycle 1 it increased from $52.56 \%$ to $58.21 \%$, while in cycle 2 it increased from $62.78 \%$ to $77.69 \%$. It can be concluded that the variation drill method can improve badminton forehand smashes in PB athletes. Malang Badminton Club. Based on the research results, it can be concluded that the variation drill method can improve badminton forehand smashes in PB athletes. Malang Badminton Club.
\end{abstract}

Keywords: forehand smash, drilll variation, badminton

\begin{abstract}
Abstrak
Tujuan penelitian ini adalah untuk meningkatkan keterampilan pukulan forehand smash bulutangkis pada atlet di PB. Malang Badminton Club Kota Malang. Penelitian ini merupakan Penelitian Tindakan Olahraga (PTO). Teknik pengumpulan data yang digunakan adalah wawancara, angket, observasi dan tes. Analisis yang digunakan adalah analisis data kualitatif dan kuantitatif. Penelitian ini dilaksanakan selama 2 siklus, setiap siklusnya terdiri dari 5 kali pertemuan. Subjek yang digunakan adalah 13 atlet. Hasil dari penelitian ini menunjukkan bahwa pada siklus 1 mengalami peningkatan dari $52.56 \%$ meningkat menjadi $58.21 \%$ sedangkan pada siklus 2 mengalami peningkatan dari $62.78 \%$ meningkat menjadi $77.69 \%$. Dapat disimpulkan bahwa metode drill variasi dapat meningkatkan pukulan forehand smash bulutangkis pada atlet PB. Malang Badminton Club. Berdasarkan hasil penelitian, dapat disimpulkan bahwa penggunaan metode drill variasi dapat meningkatkan pukulan forehand smash bulutangkis pada atlet PB. Malang Badminton Club.
\end{abstract}

Kata kunci: forehand smash, driil variasi, bulutangkis

\section{Pendahuluan}

Keberadaan olahraga di Indonesia kini sedang maju. Olahraga merupakan suatu aktivitas fisik yang dilakukan oleh berbagai kalangan usia, mulai dari usia anak-anak, remaja, dewasa, hingga lanjut usia. Olahraga di Indonesia sendiri sangat beragam. Kegiatan olahraga dilakukan orang-orang guna menjaga kondisi agar tetap sehat dan bugar. Salah satu olahraga yang populer dan digemari masyarakat Indonesia yaitu bulutangkis. Menurut (Zulbahri \& Melinda, 2019) "bulutangkis merupakan olahraga yang dimainkan menggunakan alat pukul berupa raket, dimainkan dua orang bagi tunggal dan dua pasangan bagi ganda dengan saling berlawanan atau berhadapan". Sedangkan (Akhsan, 2012) berpendapat lebih luas bahwa "bulutangkis atau badminton merupakan suatu olahraga raket yang dimainkan oleh dua orang (untuk tunggal) atau dua pasang (untuk ganda) dengan posisi berlawanan pada sebidang lapangan yang terbagi dengan sebuah net". Selain itu (Seth, 2016) juga mengemukakan 
"badminton sport is characterized variety of actions of short duration and high intensity coupled with a short resting time". Jadi olahraga bulutankis merupakan suatu olahraga raket yang dimainkan oleh dua orang atau dua pasang menggunakan alat beerupa raket pada sebidang lapangan yang terbagi dengan sebuah net dengan intensitas yang tinggi dan durasi yang singkat.

Dalam permaianan bulutangkis baik tunggal maupun ganda membutuhkan fisik, taktik, mental dan berbagai macam teknik pukulan. Menurut (Budiwanto, 2013) "terdapat beberapa pukulan dasar pada permainan bulutangkis yang wajib dikuasai oleh pemain yaitu pukulan service, pukulan lob, pukulan dropshot, pukulan smash, pukulan net, pukulan mendatar (drive)". Dari keseluruhan pukulan dasar tersebut, atlet harus menguasainya dengan baik agar dapat menjadi modal untuk berprestasi. Dari berbagai macam pukulan dasar yang harus dikuasai atlet, ada pukulan dasar yang sering digunakan mematikan pertahanan lawan sehingga bisa digunakan mendapatkan poin saat melakukan permainan bulutangkis, yaitu pukulan smash. Menurut (Hassan, 2017) "smashing performance is one of the most relevant key successes to score critical points in badminton matches". Sedangkan (Purnama, 2010) berpendapat "smash adalah suatu gerakan dari pukulan overhead yang mayoritas menggunakan kekuatan dan kecepatan lengan dengan lecutan pergelangan tangan agar bola yang dihasilan dari pukulan tersebut dapat menukik tajam ke bawah bidang dari permainan lawan". Jadi pukulan smash merupakan pukulan yang digunakan untuk mematikan pertahanan lawan dengan kekuatan dan kecepatan lengan serta pergelangan tangan yang memiliki karakteristik bola menukik tajam ke bawah.

Dalam mencapai prestasi, atlet perlu melakukan latihan. Latihan merupakan cara atlet agar dapat meningkatkan dan menguasai fisik, taktik, mental dan berbagai macam teknik pukulan yang ada dalam bulutangkis. (Budiwanto, 2012) mengemukakan bahwa "latihan merupakan bentuk kegiatan olahraga yang dilaksanakan menggunakan suatu program yang pada prakteknya disusun secara terstruktur dan teratur, guna agar dapat menambah serta meningkatkan kemampuan yang dimiliki oleh atlet sebagai upaya untuk memperoleh suatu prestasi, terutama digunakan dalam persiapan untuk menghadapi pertandingan". Dalam latihan tentu ada peran pelatih dalam penyusunan program latihan bagi atlet. (Harsono, 2015) menyatakan bahwa "tugas pelatih yaitu mempersiapkan atletnya dengan baik dalam menghadapi pertandingan agar mampu berprestasi sebaik mungkin. Agar persiapan efektif, pelatih perlu melakukan penyusunan program untuk mengembangkan kemampuan atlet baik dalam aspek teknik, keterampilan, taktik, kondisi fisik serta kondisi faaliah tubuhnya (conditioning), termasuk aspek psikologisnya".

Seperti latihan yang dilakukan oleh PB. Malang Badminton Club, yang beralamatkan di Jalan Terusan Rajabasa Nomer 5 Pisang Candi Kecamatan Sukun, Kota Malang. Klub ini memiliki 3 orang pelatih yang diketuai oleh Bapak Ahmad Ilham Habibi dan memiliki atlet sebanyak 30 atlet. Terdiri dari 13 atlet di tim A dan 17 atlet di tim B. Untuk tim A adalah tim yang terdiri dari atlet-atlet yang berlatih untuk tujuan prestasi dengan usia 10-12 tahun, sedangkan untuk tim B adalah tim yang terdiri dari atlet-atlet yang berlatih untuk tujuan kesehatan dengan usia 7-12 tahun. Kegiatan latihan di PB. Malang Badminton Club dalam setiap minggunya dilaksanakan sebanyak 3 kali pertemuan pada hari rabu, jum'at minggu mulai 
pukul 16.00 sampai pukul 18.00 WIB. Observasi awal dilakukan pada tanggal 15 November 2019, melibatkan 13 atlet dari tim A terdiri dari 5 atlet putri dan 8 atlet putra dengan cara melakukan permainan bulutangkis tunggal sesungguhnya menggunakan poin 11 secara bergantian. Observasi dilakukan dengan mengamati teknik dasar pukulan atlet oleh 1 observer diambil dari salah satu pelatih PB. Malang Badminton Club dan telah memiliki lisensi.

Berdasarkan hasil observasi yang telah dilakukan, dari total intensitas 116 pukulan atlet yang mampu melakukan service dengan benar sebesar $84.48 \%$ dan tingkat kesalahan sebesar 15.51\%. Dari total intensitas 193 pukulan atlet yang mampu melakukan lob dengan benar sebesar $78.75 \%$ dan tingkat kesalahan sebesar 21.24\%. Dari total intensitas 94 pukulan atlet yang mampu melakukan smash dengan benar sebesar 37.23\% dan tingkat kesalahan sebesar 62.76\%. Dari total intensitas 93 pukulan atlet yang mampu melakukan net dengan benar sebesar $62.36 \%$ dan tingkat kesalahan sebesar 37.63\%. Dari total intensitas 116 pukulan, atlet yang mampu melakukan dropshot dengan benar sebesar $57.75 \%$ dan tingkat kesalahan sebesar $42.24 \%$. Dari total intensitas 100 pukulan, atlet yang mampu melakukan drive dengan benar sebesar $62 \%$ dan tingkat kesalahan sebesar 38\%. Dari data observasi, diketahui bahwa teknik pukulan smash memiliki tingkat kesalahan tertinggi diantara pukulan yang lain. Agar peneliti data yang lebih detail mengenai hasil observasi yang telah dilaksanakan, maka pada tanggal 20 November 2019 peneliti melaksanakan tes keterampilan pukulan smash terhadap atlet di PB. Malang Badminton Club

Dari hasil tes keterampilan pukulan smash yang telah dilakukan, menunjukkan bahwa atlet masih banyak melakukan kesalahan pada sikap persiapan sebesar 53.85\%, sikap memukul shuttlecock dengan persentase kesalahan sebesar $61.54 \%$, sedangkan sikap lanjutan dengan persentase kesalahan sebesar 53.84\%. Hal tersebut menunjukkan bahwa keterampilan pukulan smash dari atlet PB. Malang Badminton Club masih kurang baik. Pada saat dilakukannya tes keterampilan smash masih banyak atlet yang melakukan kesalahan dalam gerakan maupun saat memukul shuttlecock yang membuat shuttlecock menjadi tanggung dan kurang menukik. Hal ini disebabkan karena penguasaan atlet yang kurang terhadap keterampilan forehand smash, serta atlet kurang baik dalam mengikuti program latihan. Pada saat latihan banyak atlet yang mengobrol dan bergurau dengan temannya serta variasi latihan yang kurang dan monoton.

Hasil informasi yang didapatkan pada wawancara dengan pelatih menyebutkan, atlet terkesan pasif dalam mengikuti latihan. Keterbatasan waktu dan lapangan yang digunakan latihan serta kurangnya latihan yang bervariasi menyebabkan atlet menjadi bosan. Hasil angket yang disebar pada atlet PB. Malang Badminton Club juga menunjukkan dari 13 atlet, 69.23\% (9 atlet) memilih bahwa pukulan smash adalah pukulan yang sulit untuk dilakukan. Hasil tersebut juga didukung dari data hasil wawancara yang diperoleh dari pelatih, yang mengatakan bahwa pukulan smash adalah pukulan yang masih sulit untuk ditingkatkan. Padahal pukulan smash dalam bulutangkis sering digunakan untuk mematikan pertahanan lawan sehingga dapat menyumbangkan banyak poin. Pelatih juga menyampaikan bahwa latihan teknik pukulan yang sering diberikan pelatih adalah forehand lob sedangkan untuk metode latihan yang digunakan untuk meningkatkan teknik pukulannya yaitu metode stroke (pola pukulan). Maka perlu adanya upaya untuk mengatasi masalah atlet PB. Malang 
Badminton Club Kota Malang, guna menunjang permainan dan prestasi atlet ke depannya. Dari latar belakang dan hasil observasi tersebut, maka peneliti perlu untuk melakukan Penelitian Tindakan Olahraga mengenai: Upaya Meningkatkan Keterampilan Pukulan Forehand Smash Bulutangkis Menggunakan Metode Drill Variasi Bagi Atlet PB. Malang Badminton Club Kota Malang.

\section{Metode}

Pada penelitian ini menggunkan jenis Penelitian Tindakan Olahraga (PTO). Jenis penelitian ini merupakan penelitian yang diadaptasi Penelitian Tindakan Kelas (PTK). Pendekatan yang digunakan adalah pendekatan kuantitatif dan kualitatif karena pendekatan ini bertujuan mencari data secara merata dan menyeluruh tentang keterampilan forehand smash bulutangkis. Data yang dikumpulkan mengenai pukulan forehand smash, diperoleh dari hasil wawancara, angket, observasi dan tes permainan pada saat proses latihan. Sedangkan untuk sumber data dari penelitian ini diperoleh dari 13 atlet terdiri dari 8 laki-laki dan 5 perempuan. Teknik pengumpulan data yang digunakan pada penelitian ini adalah tes dan observasi. Analisis data dari penelitian ini menggunakan analisis data kualitatif dan analisis data kuantitatif. Data yang bersifat kualitatif diubah menjadi data berbentuk kuantitatif dengan cara menggunakan angka 1 pada indikator yang menunjukkan tanda $(\sqrt{ })$ dan angka 0 berarti indikator menunjukkan tanda (-). Pada saat proses latihan pukulan forehand smash, dapat dikatakan berhasil atau masih kurang dianalisis menggunakan rumus deskriptif persentase milik (Sudijono, 2011) dalam pengolahan datanya. Kemudian dari hasil persentase yang telah dihitung tersebut maka dapat dilihat hasil klasifikasinya pada tabel di bawah:

Tabel 1. Taraf Keberhasilan Tindakan

\begin{tabular}{lll}
\hline Taraf keberhasilan Tindakan & Keterangan & Makna \\
\hline $81-100 \%$ & Sangat baik & Digunakan \\
$61-80 \%$ & Baik & Digunakan \\
$41-60 \%$ & Cukup & Digunakan \\
$21-40 \%$ & Kurang & Diperbaiki \\
$0-20 \%$ & Sangat Kurang & Diganti \\
\hline
\end{tabular}

(Sumber: Suharsimi Arikunto \& Jabar, 2014)

Jika pelaksanaan tindakan yang diberikan belum mencapai 61\%, maka peneliti melakukan refleksi kembali agar mengetahui dimana letak kesalahan sehingga perlu adanya tindakan perbaikan. Di dalam penelitian ini menggunakan beberapa siklus, dalam setiap siklus memiliki alur. Alur-alur dari setiap siklusnya sebagai berikut: a) perencanaan, b) pelaksanaan, c) pengamatan, d) refleksi. Berikut ilustrasi dari siklus PTK menurut (Suharsimi Arikunto dkk., 2012).

Alur siklus pada PTO meliputi: perencanaan tindakan, pelaksanaan tindakan, pengamatan, dan refleksi. Umumnya penelitian tindakan kelas dilakukan selama 3 kali pertemuan disetiap siklusnya. Akan tetapi, pada penelitian ini peneliti menggunakan 5 kali pertemuan pada setiap siklusnya. Berikut adalah penjelasan dari alur pada Gambar 1 . 


\subsection{Siklus 1}

Berikut adalah uraian dari alur dalam pelaksanaan penelitan tindakan kelas yang terdapat pada siklus 1:

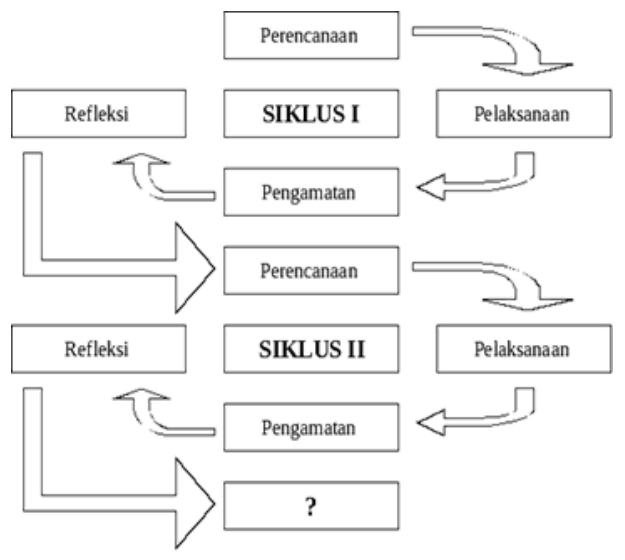

\section{Gambar 1. Alur Pelaksanaan Penelitian Tindakan Kelas}

\subsubsection{Perencanaan}

Kegiatan yang dilakukan pada perencanaan tindakan 1 adalah: 1) membuat rancangan program latihan, 2) mempersiapkan sarana dan prasarana yang digunakan, 3) mempersiapkan instrumen yang digunakan untuk latihan.

\subsubsection{Pelaksanaan}

Pada tahapan ini kegiatan yang akan dilaksanakan oleh atlet adalah melakukan proses latihan pukulan forehand smash menggunakan metode drill variasi yang telah ditentukan pada perencanaan tindakan yang sebelumnya telah disusun peneliti.

\subsubsection{Pengamatan}

Kegiatan ini digunakan untuk mengamati kejadian-kejadian yang ada pada saat proses pelaksanaan tindakan. Kejadian-kejadian ini diamati oleh peneliti, pelatih, maupun 1 observer yang telah berlisensi. Observasi ini berisi catatan-catatan berupa peristiwa maupun situasi dan kondisi di lapangan yang terjadi pada saat proses latihan berlangsung.

\subsubsection{Refleksi}

Kegiatan yang dilakukan pada tahapan ini yaitu mengolah dan menganalisis data. Refleksi ini dilakukan oleh peneliti dengan pelatih berdasarkan hal-hal pada saat proses perencanaan tindakan, pelaksanaan tindakan, maupun pada saat proses pengamatan untuk menemukan temuan-temuan pada saat melakukan latihan forehand smash. 


\subsection{Siklus 2}

Siklus 2 ini dilaksanakan apabila pada siklus 1 pemberian tindakan tidak mengalami peningkatan sesuai taraf keberhasilan yang telah ditentukan oleh peneliti yaitu sebesar $61 \%$. Tahapan-tahapan pada siklus 2 ini sama seperti tahapan pada siklus 1. Apabila setelah dilakukannya siklus 2 hasilnya telah memenuhi persentase keberhasilan tindakan yang ditentukan maka penelitian tidak perlu dilanjutkan pada siklus selanjutnya. Akan tetapi, apabila hasil dari siklus 2 belum mencapai dari persentase keberhasilan tindakan yang telah ditentukan maka perlu adanya tindak lanjut atau perlu adanya penelitian lanjutan ke siklus 3 dan seterusnya.

\section{Hasil dan Pembahasan}

Hasil data dari siklus 1 dan siklus 2 dapat dilihat pada tabel di bawah ini:

Tabel 2. Hasil Siklus 1 dan Siklus 2

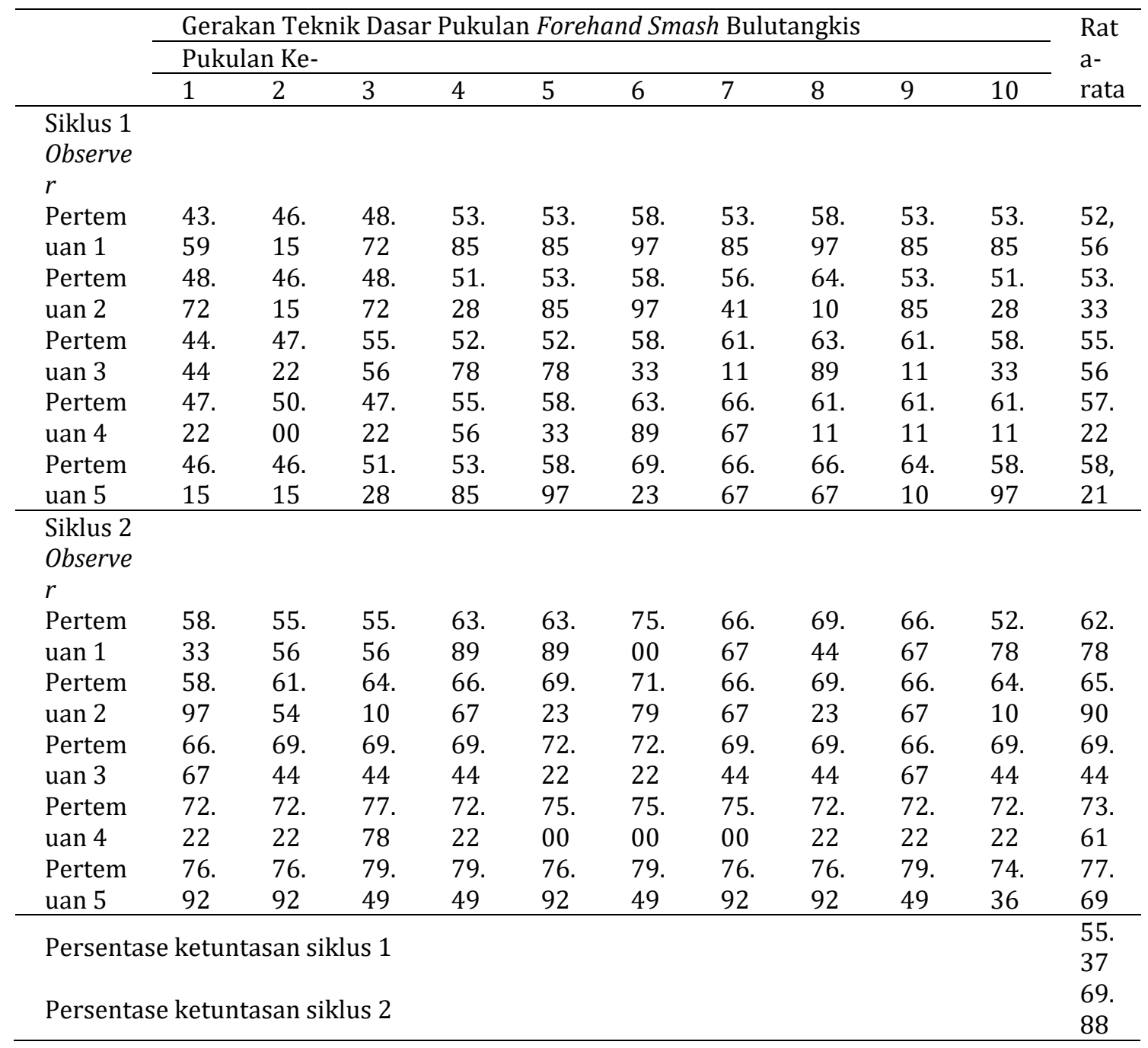


Hasil analisis yang dilakukan dari peneliti menunjukkan bahwa pada siklus 1 dan siklus 2 terdapat peningkatan persentase ketuntasan yang baik. Persentase keberhasilan tindakan pada siklus 1 pertemuan 1 sebesar $58.2 \%$ dan pada siklus 1 pertemuan 5 sebesar $58.21 \%$ dengan rerata sebesar $55.37 \%$, sedangkan persentase keberhasilan tindakan pada siklus 2 pertemuan 1 sebesar $62.78 \%$ dan pada siklus 2 pertemuan 5 sebesar $77.69 \%$ dengan rerata sebesar $69.88 \%$. Sesuai dengan persentase keberhasilan tindakan yang telah ditentukan sebesar $61 \%$, maka hasil dari penelitian ini yaitu sebesar $69.88 \%$ sudah dikatakan dalam kategori baik dan dapat digunakan. Sehingga dapat disimpulkan bahwa penggunaan metode driil variasi dapat meningkatkan keterampilan pukulan forehand smash pada atlet PB. Malang Badminton Club.

\subsection{Temuan Siklus 1}

Pada sikap memukul memiliki grafik yang paling rendah dibandingkan dengan sikap persiapan dan sikap lanjutan. Indikator pada sikap memukul meliputi: 1) ayunan raket kedepan atas dan shuttlecock dipukul setinggi mungkin dari jangkauan raket, 2) gerakan disertai lecutan dari pergelangan tangan, 3) berat badan dipindah ke kaki kiri disertai dengan memutar badan dan bahu kanan sehingga posisi dada menghadap ke net. Kebanyakan atlet melakukan kesalahan pada indikator ke 2 dan 3, tepatnya pada gerakan lecutan dari pergelangan tangan serta pada indikator memutar badan dan bahu tangan yang tidak dilakukan. Hal tersebut dapat disebabkan karena kurangnya kelentukan, kelenturan, maupun kekuatan dari pergelangan tangan, lengan maupun bahu yang dimiliki oleh atlet PB. Malang Badminton Club. Menurut (Ng \& Lam, 2002) menyatakan "sport involve repetitive overarm moton like badminton, tennis, or baseball require well coordinated and synchronized of the shoulder muscle" yang berarti dalam olahraga seperti bulutangkis, tenis, dan baseball memerlukan koordinasi dan sinkronisasi dari otot bahu. Dalam bermain bulutangkis khususnya pada saat melakukan forehand smash hal tersebut sangat penting dan menurut (Nurmala et al., 2020) mengatakan bahwa "dari kelenturan sendi bahu terhadap kemampuan forehand smash terdapat hubungan yang signifikan".

Selain dari temuan diatas, juga terdapat temuan bahwa terdapat penurunan pada akhirakhir hasil pukulan dari 10 kali percobaan pukulan forehand smash yang dilakukan oleh atlet PB. Malang Badminton Club. Pada awal saat atlet melakukan pukulan, atlet terlihat masih bersemangat dan bertenaga dalam pelaksanaannya, sedangkan pada saat memasuki akhir pukulan terdapat penurunan. Hal tersebut juga berpengaruh terhadap kualitas serta kemampuan pukulan yang mereka miliki. Kondisi tersebut dapat dipengaruhi oleh kondisi fisik atlet yang kurang baik. Sementara itu dalam olahraga kondisi fisik juga merupakan unsur yang vital, terutama dalam bulutangkis. Dimana pemain bulutangkis dituntut agar aktif bergerak seperti memukul shuttlecock, berlari, berlompat, serta mengubah arah gerakannya secara cepat dan tepat. Hal tersebut diperkuat oleh pernyataan (Himawan \& Permadi, 2019) yang mengatakan bahwa "kondisi fisik yang prima sangat diperlukan agar dapat melakukan gerakan dan aktivitas dalam bulutangkis tanpa mengalami kendala dan dengan kondisi fisik dapat mengembangkan teknik yang dimiliki serta menunjang gerakan teknik yang diperagakan oleh pemain dengan baik". Kurangnya baiknya kondisi fisik yang berpengaruh 
terhadap kemampuan teknik yang dimiliki tersebut dapat terjadi dan disebabkan oleh beberapa faktor.

Beberapa faktor yang mempengaruhi kondisi fisik adalah kurang terprogramnya latihan, kurang efektifnya metode, serta kurangnya porsi latihan. Mengingat dari wawancara yang dilakukan oleh peneliti kepada ketua PB. Malang Badminton Club yang mengatakan bahwa latihan dilakukan sebanyak 3 kali dalam seminggu dengan intensitas setiap pertemuannya adalah 2 jam menggunakan 2 lapangan, sehingga bisa dikatakan untuk porsi latihannya masih kurang. (Muin dkk., 2019) menyatakan bahwa "latihan kondisi fisik harus disusun dalam perencanaan yang baik, tertata dan terstruktur agar kemampuan fungsional dari tubuh dapat bekerja dengan baik dan sebagaimana mestinya". Sedangkan menurut (Noviantoro \& Purnomo, 2018) mengatakan bahwa "penyusunan program latihan yang terorganisir, metodis serta ilmiah merupakan alat yang penting bagi pelatih agar pelaksanaan training berjalan dengan baik dan hasilnya meningkat".

Kemudian pada saat pelaksanaan shadow terdapat temuan berupa kurangnya kelincahan footwork yang dimiliki oleh atlet. Dalam bermain bulutangkis footwork digunakan untuk mengubah arah secara efektif dan efisien agar mempermudah saat bergerak dan memukul shuttlecock di atas lapangan sehingga tenaga yang dikeluarkan oleh atlet tidak terlalu besar. (Gustaman, 2019) mengatakan bahwa "dalam bermain bulutangkis, mengatur kaki sangat diperlukan karena seorang pemain tidak dapat mengontrol dan memukul shuttlecock dengan mudah apabila tidak dalam posisi yang tepat dan efisien". Sedangkan (Subarkah dkk., 2019) mengatakan "footwork training is basis for being able to determine the quality of punch. A good footwork allows athlete to move faster and efficiently in various direction and is better prepared to take or give more varied and quality blows" yang berarti bahwa latihan gerak kaki yang baik dianggap penting untuk meningkatkan kualitas pukulan. Karena dengan gerak kaki yang baik pula dapat memungkinkan atlet agar dapat bergerak lebih cepat dan lebih efisien ke berbagai arah dan lebih siap menerima atau mengembalikan pukulan dengan lebih variatif dan berkualitas. Sehingga apabila footwork yang dimiliki kurang, akan berakibat pada tingkat antisipasi atlet terhadap datangnya shuttlecock menjadi rendah. Menurut (Islamiah \& Sepdanius, 2019) "lambatnya footwork yang dimiliki oleh atlet menyebabkan keterlambatan dalam memukul shuttlecock". Hal ini, juga dapat menjadi penyebab kurangnya keterampilan atlet dalam melakukan pukulan forehand smash, karena timing dalam memukul kurang tepat.

Terdapat beberapa hal yang berkaitan dengan footwork menurut (Edmizal et al., 2020)menyatakan bahwa "kemampuan atlet dalam footwork berkaitan erat dengan otot tungkai terutama kecepatan reaksi dan daya ledak dari tungkai". Dalam meningkatkan kemampuan footwork dapat dilakukan beberapa latihan seperti menurut (Hung dkk., 2020) mengatakan bahwa "in addition to shadow training, the agility ladder or plyometric training should be included in the training program to improve the limbs muscle" yang berarti bahwa selain laihan bayangan, agility ladder dan latihan plyometric perlu dimasukkan ke dalam program latihan untuk meningkatkan kemampuan otot tungkai. Sedangkan menurut (Putra dkk., 2017) menyatakan bahwa "pemberian latihan footwork selama 16 kali pertemuan dengan frekuensi sebanyak 3 kali pertemuan dalam seminggu meghasilkan rata-rata waktu 12.26 detik dari rata-rata waktu sebelumnya adalah 13.60 detik". 


\subsection{Temuan Siklus 2}

Pada siklus 2 terdapat peningkatan yang pada setiap pertemuan. Akan tetapi masih terdapat beberapa atlet yang kurang dalam hal akurasi pukulan forehand smash, sehingga menyebabkan hasil dari pukulan tidak tepat sasaran. Hasil pukulan forehand smash yang dilakukan oleh atlet mengarah melebar dan keluar ke sisi-sisi lapangan. Padahal dalam bermain bulutangkis pukulan smash digunakan sebagai senjata untuk mendapatkan poin. Kurangnya akurasi yang dimiliki oleh atlet di PB. Malang Badminton Club dapat disebabkan oleh kurangnya koordinasi mata dan kemampuan serta hal-hal yang berhubungan dengan tangan yang dimiliki oleh atlet. Selain keterampilan yang baik, atlet juga harus memiliki akurasi yang baik dalam bermain bulutangkis khususnya dalam melakukan pukulan forehand smash. Menurut (Sesar \& Komar, 2018) menyatakan bahwa "koordinasi antara mata tangan merupakan suatu kesatuan, yaitu mata bertugas sebagai pemegang fungsi utama sedangkan tangan bertugas sebagai pemegang fungsi dalam hal mengarahkan terhadap suatu gerakan tertentu". Sedangkan (Akbari dkk., 2018) mengatakan "by utilizing swing strength and arm muscle strength assisted by other bodily movements is producing a strong and hard hit and swing arm movement combined with good flexibility make a good shot too" yang berarti dengan memanfaatkan kekuatan ayunan dan kekuatan otot lengan dibantu dengan gerakan tubuh yang lain maka akan menghasilkan pukulan yang kuat dan keras. Gerakan ayunan lengan yang dikombinasikan dengan fleksibilitas juga akan menghasilkan pukulan yang baik juga. Selain itu (Lisdiantoro, 2016) juga berpendapat bahwa antara koordinasi mata tangan, power otot lengan dan kekuatan otot perut dengan akurasi serta kemampuan dalam pukulan forehand smash terdapat hubungan yang signifikan. Perlu adanya latihan yang variatif guna meningkatkan akurasi yang dimiliki oleh atlet.

Ada banyak bentuk latihan untuk meningkatkan akurasi, salah satunya menggunakan latihan Variasi Target Game. Menurut (Yusup dkk., 2020)"terdapat peningkatan yang signifikan dari pemberian variasi target game, dengan rerata pada pre-test sebesar 28.00 sedangkan rerata pda post-test sebesar 33.00". Selain akurasi, hal yang menjadi temuan dalam siklus 2 ini adalah mengenai kedisiplinan dari atlet yang masih sering terlambat dalam hal kehadiran serta kurangnya kesadaran dan kedisiplinan diri yang dimiliki atlet dalam melaksanakan program latihan yang diberikan. Dalam seluruh cabang olahraga, kedisiplinan sangat penting. Semakin kedisiplinan tersebut tertanam dalam diri atlet, maka akan semakin tinggi pula peluang atlet untuk dapat memperoleh kemampuan serta prestasi yang maksimal. Menurut (Sin, 2005) menyatakan bahwa "berhasilnya suatu latihan dapat dipengaruhi kedisiplinan, agar tujuan tersebut dapat dicapai atlet dengan baik maka seorang atlet harus memiliki kedisiplinan yang baik pula".

Peran pelatih sangat fundamental dalam latihan, (Misbakhudin \& Mohamad, 2020) "dalam suatu latihan peran pelatih sangat penting seperti mengajarkan kedisiplinan, tanggung jawab, memotivasi atlet, dan membangun rasa percaya diri pada diri atlet guna mengembangkan serta meningkatkan kemampuannya sehingga dapat mengantarkan atlet menuju prestasi yang baik". Perlu adanya usaha dlam mwujudkan hal tersebut, yaitu berupa dengan komunikasi yang baik antara pelatih dengan atlet, seperti yang dikatakan oleh (Mohd Kassim dkk., 2020) yang menyatakan bahwa "coach are responsible for explain and describe, to 
be able demonstrate, make the atlhlete understand and for provide feedback of the taks in training session or in competition. Thereofer, this is not just about learn and improve the skill, but it also creat positive environment and relations for better result" yang berarti pelatih bertanggungjawab untuk mendeskripsikan, menjelaskan, mendemonstrasikan memberikan umpan balik pada saat latihan maupun kompetisi. Jadi, ini bukan hanya tentang belajar atau sekedar meningkatkan keterampilan, akan tetapi juga membuat lingkungan dan hubungan yang positif untuk mendapatkan hasil yang baik.

Pelatih perlu memiliki komunikasi yang baik serta memberikan motivasi kepada atlet agar timbul rasa tanggung jawab dari dalam dirinya untuk melaksanakan tugasnya. Bentuk komunikasi yang digunakan oleh seorang pelatih dapat menggunakan komunikasi interpersonal menurut (Sutirta \& Sukendro, 2020) "dalam membangun motivasi serta komunikasi pelatih dapat menerapkan komunikasi interpersonal seperti kontak langsung dengan memberikan reward atau gift kepada pemain /atlet yang berlatih dengan baik". Maka dari itu, selain dengan memberikan hukuman pada atlet yang sering datang terlambat dan tidak berlatih dengan serius, pelatih juga dapat memberikan reward pada atlet yang disiplin dan berlatih dengan baik sehingga muncul motivasi pada atlet yang lain untuk lebih disiplin dan berlatih lebih baik lagi.

Setelah penelitian yang dilaksanakan pada siklus 1 dan siklus 2 terlaksana, hasil yang diperoleh setelah diberikan tindakan mengenai keterampilan pukulan forehand smash pada atlet PB. Malang Badminton Club mengalami peningkatan yang baik. Sesuai dengan persentas ketuntasan yang telah ditentukan sebesar 61\%, maka hasil dari penelitian ini yaitu sebesar $69.88 \%$ sudah dikatakan dalam kategori baik dan dapat digunakan. Sehingga hasil dari kesimpulan penelitian ini menunjukkan bahwa penggunaan metode driil variasi dapat meningkatkan keterampilan pukulan forehand smash pada atlet PB. Malang Badminton Club Kota Malang. Seperti penelitian dari (Rustandi \& Safitri, 2019) bahwa "terdapat pengaruh yang signifikan dari pemberian metode drill terhadap hasil smash siswa ekstrakurikuler bulutangkis di SMK Negeri 1 Lemahabang Kecamatan Lemahabang Kabupaten Cirebon". Sedangkan menurut (Anggraini dkk., 2020) "dengan penggunaan model latihan metode drill dapat meningkatkan keterampilan pukulan backhand clear bagi atlet PB. Eka Jaya Sidoarjo". Selain itu menurut (Fattahudin dkk., 2020) "dengan menggunakan model variasi latihan dapat meningkatkan pukulan forehand smash". Jadi, dengan menggunakan metode drill variasi yang diberikan secara berulang-ulang dan disusun secara variatif dapat meningkatkan keterampilan atlet dalam teknik pukulan forehand smash pada atlet PB. Malang Badminton Club Kota Malang.

\section{Simpulan}

Berdasarkan dari hasil penelitian yang telah dilakukan oleh peneliti, maka dapat ditarik kesimpulan bahwa terdapat peningkatan yang baik terhadap keterampilan forehand smash yang telah diberikan metode drill variasi pada atlet PB. Malang Badminton Club Kota Malang. Hasil pada pertemuan 1 siklus 1 sebesar $52.56 \%$ meningkat menjadi $58.21 \%$, sedangkan hasil pada pertemuan 1 siklus 2 sebesar $62.78 \%$ meningkat menjadi $77.69 \%$. Dari hasil yang didapatkan tersebut telah melampaui persentase keberhasilan tindakan yang ditentukan yaitu sebesar $61 \%$ dengan klasifikasi baik dan dapat digunakan, maka tujuan penggunaan metode 
drill variasi untuk meningkatkan pukulan forehand smash pada atlet PB. Malang Badminton Club Kota Malang dapat dikatakan tercapai dan berhasil.

\section{Daftar Rujukan}

Akbari, M., Dlis, F., \& Widiastuti, W. (2018). the Effect At Muscle Power Arm, Hand-Eye Coordination, Flexibility and Self Confidence Upon Badminton Smash Skill. Jipes - Journal of Indonesian Physical Education and Sport, 4(1), 57-64. https://doi.org/10.21009/jipes.041.05

Akhsan, H. (2012). Mahir Bulutangkis. Nusa Cendikia.

Anggraini, Y., Januarto, O. B., \& Kurniawan, R. (2020). Upaya Peningkatan Pukulan Backhand Clear Bulutangkis Menggunakan Metode Drill. Sport Science and Health, 2(9), 440-445.

Budiwanto, S. (2012). Metodologi Latihan Olahraga. In FIK Universitas Negeri Malang.

Budiwanto, S. (2013). Dasar-dasar Teknik dan Taktik Bermain Bulutangkis. Universitas Negeri Malang.

Edmizal, E., Donie, D., \& Soniawan, V. (2020). Kecepatan Reaksi dan Daya Ledak Otot Tungkai Berkontribusi terhadap Kemampuan Footwork Bulutangkis. Sporta Saintika, 5(2), 120-132.

Gustaman, G. P. (2019). Hubungan Footwork, Kekuatan Otot Tungkai Dan Tinggi Lompatan Terhadap Kemampuan Smash Bulutangkis. JUARA: Jurnal Olahraga, 4(1), 1. https://doi.org/10.33222/juara.v4i1.512

Harsono, H. (2015). Periodesasi Program Pelatihan (Cetakan Pe). Bandung: PT Remaja Rosdakarya.

Hassan, I. H. I. (2017). The Effect of Core Stability Training on Dynamic Balance and Smash Stroke Performance in Badminton Players. International Journal of Sports Science and Physical Education, 2(3), 44-52.

Himawan, M. R., \& Permadi, A. G. (2019). Analisis Unsur Kondisi Fisik Dominan Atlit Bulutangkis Pb. Satria Dompu Tahun 2019. Jurnal Ilmu Sosail Dan Pendidikan, 3(3), 94-101.

Hung, M. H., Chang, C. Y., Lin, K. C., Hung, C. L., \& Ho, C. S. (2020). The Applications of Landing Strategies in Badminton Footwork Training on a Backhand Side Lateral Jump Smash. Journal of Human Kinetics, 73(1), 19-31. https://doi.org/10.2478/hukin-2020-0002

Lisdiantoro, G. (2016). Hubungan Antara Koordinasi Mata Tangan, Power Otot Lengan Dan Kekuatan Otot Perut Dengan Kemampuan Pukulan Smash Dalam Permainan Bulutangkis. Premiere Educandum: Jurnal Pendidikan Dasar Dan Pembelajaran, 6(02), 210-221. https://doi.org/10.25273/pe.v6i02.813

Misbakhudin, M., \& Mohamad, A. (2020). Indonesian Journal for Pembinaan Prestasi Olahraga Sepak Bola Pada SSB Barca Temanggung di Kabupaten Temanggung. Indonesian Journal for Physical Education and Sport, 1(1), 33-40.

Mohd Kassim, A. F., Wan Abdullah, W. F. I., Md Japilus, S. J., \& Azanuar Yusri, A. S. (2019, September). CoachAthlete Relationship and Coaching Effectiveness in Team Sports Athletes. In International Conference on Movement, Health and Exercise (pp. 451-462). Springer, Singapore.

Muin, M., Nur, A., \& Akhmady, A. L. (2019). Analisis Kondisi Fisik Atlit Pomnas Cabang Olahraga Bulutangkis Maluku Utara Tahun 2019. JUPE: Jurnal Pendidikan Mandala, 4(5), 276-280.

Ng, G. Y. F., \& Lam, P. C. W. (2002). A study of antagonist/agonist isokinetic work ratios of shoulder rotators in men who play badminton. Journal of Orthopaedic and Sports Physical Therapy, 32(8), 399-404. https://doi.org/10.2519/jospt.2002.32.8.399

Noviantoro, W. H., \& Purnomo, M. (2018). Evaluasi Program Kondisi Fisik Cabang Olahraga Bulutangkis Pb Surabaya. Jurnal Prestasi Olahraga, 1(3), 1-7.

Nurmala, J. L. O. M., \& Muh. Zaenal, A. (2020). Hubungan Kelenturan Sendi Bahu dengan Kemampuan Smash Forehand Bulutangkis Pada Siswa SMP Negeri 15 Kendari. JOKER (Jurnal Ilmu Keolahragaan), 1(02), 111.

Purnama, S. K. (2010). Kepelatihan Bulutangkis Modern. In Surakarta: Yuma Pustaka.

Putra, A. K., Ramadi, Putu, N., \& Wijayanti, N. (2017). The Effect of Footwork for Agility At Men Athlete of Persatuan Bulutangkis Mandiri Pekanbaru U-15. Jurnal Online Mahasiswa, 4(1), 1-8. 
Rustandi, E., \& Safitri, S. (2019). Pengaruh Metode Drill Terhadap Hasil Smash Siswa Ekstrakulikuler Permainan Bulutangkis Smk Negeri 1 Lemahabang Kecamatan Lemahabang Kabupaten Cirebon. Journal Respecs, 1(2), 68. https://doi.org/10.31949/jr.v1i2.1472

Islamiah, S., \& Sepdanius, E. (2019). Pengaruh Latihan Footwork dan Latihan Shadow Terhadap Agility pada Atlet Putra Persatuan Bulutangkis ILLVERD. Jurnal Stamina, 2(10), 54-64.

Sesar, D. R. N., \& Komari, A. (2018). Hubungan Koordinasi Mata Tangan Dengan Ketepatan Pukulan Lob Bulutangkis Klub Jogjaraya Kota Gede Tahun 2017/2018. PGSD Penjaskes, 7(3), 1-14.

Seth, B. (2016). Determination factors of badminton game performance Bipasa. International Journal of Physical Education, Sports and Health, 3(1), 20-22. https://doi.org/10.1016/0006-2952(80)90515-8

Sin, T. H. (2005). Tjung Hauw Sin. Saat Ini Dosen Jurusan Kepelatihan Fakultas Ilmu Keolahragaan Universitas Negeri Padang. Ilmu Keolahragaan, Disiplin Atlet Dalam Latihan, 240-251.

Subarkah, A., Marani, I. N., \& Nurfitranto, N. (2019). The Effectiveness of Footwork Exercises to Improve Agility in Badminton. Prosiding ICOPESH Ke-1, 14-17.

Sudijono, A. (2011). Pengantar Statistik Pendidikan. In Anas Sudijono.

Arikunto, S., \& Jabar, C. S. A. (2014). Evaluasi Program Pendidikan. PT Bumi Aksara.

Arikunto, S. (2012). Penelitian Tindakan Kelas. PT Bumi Aksara.

Sutirta, V. F., \& Sukendro, G. G. (2020). Kreativitas Seorang Pelatih dalam Membangun Motivasi Berlatih pada Pemain Futsal (Studi Kasus Conan Futsal Academy). Koneksi, 4(2), 358. https://doi.org/10.249$12 / \mathrm{kn} . v 4 \mathrm{i} 2.8198$

Yusup, Y., Hidasari, F. P., \& Haetami, M. (2020). Pengaruh Variasi Target Game Terhadap Peningkatan Ketepatan Pukulan Smash Bulu Tangkis. Jurnal Pendidikan Dan Pembelajaran Khatulistiwa, 9(4), 1-7.

Zulbahri, Z., \& Melinda, C. (2019). Metode Practice Style dan Guided Discovery Style Serta Keterampilan Teknik Dasar Atlet Bulutangkis. Prosiding SENFIKS (Seminar Nasional Fakultas Ilmu Kesehatan Dan Sains), 1(1), 28-37. 